Swarthmore College

Works

Psychology Faculty Works

Psychology

$9-1-2015$

\title{
From Mirroring To World-Making: Research As Future Forming
}

Kenneth J. Gergen

Swarthmore College, kgergen1@swarthmore.edu

Follow this and additional works at: https://works.swarthmore.edu/fac-psychology

Part of the Psychology Commons

Let us know how access to these works benefits you

\section{Recommended Citation}

Kenneth J. Gergen. (2015). "From Mirroring To World-Making: Research As Future Forming". Journal For The Theory Of Social Behaviour. Volume 45, Issue 3. 287-310. DOI: 10.1111/jtsb.12075

https://works.swarthmore.edu/fac-psychology/797

This work is brought to you for free by Swarthmore College Libraries' Works. It has been accepted for inclusion in Psychology Faculty Works by an authorized administrator of Works. For more information, please contact myworks@swarthmore.edu. 
Winner of the 2014 essay competition, Independent Social Research Foundation, London, UK In press: Journal for the Theory of Social Behaviour

\title{
From Mirroring to World-Making: Research as Future Forming
}

\author{
Kenneth J. Gergen \\ Swarthmore College \\ The Taos Institute
}

\begin{abstract}
The "science wars" of recent decades have largely subsided, giving way to what might be viewed as a condition of reflective pragmatism. However, the prevailing metaphor underlying most research across the social sciences remains that of the "mirror." That is, even while conscious of its biases, researchers continue the attempt to reflect, explore, illuminate, or describe aspects of individual or social life. After considering some of the shortcomings of the prevailing practices, I offer an alternative to the mirror metaphor, one that defines the researcher in terms of world-making. By this I mean an orientation to inquiry in which the major attempt is not to assay the world for what it is, but to actively shape the contours of the future. A future forming orientation is especially invited by the increasingly rapid fluctuations in social life, and represents an alternative to the prevailing tradition and its unclear consequences for society. Shifting from a view of knowledge as propositional, to one of knowledge as praxis - or practical "knowing how" - I discuss research in a future forming direction, including critical inquiry, the creation of new practices, and collaborative action. Attention is also given to the role of theory, and to a relational ethic of research.
\end{abstract}


To foreshadow the direction of this offering, one might usefully reflect on the contribution of the past century of social science research to society and to the world. From the hundreds of thousands of studies - the countless hours of devotion by talented and educated professionals - what has resulted? What new policies, practices, or forms of daily life have emerged? Have our traditional practices of research added significantly to human wellbeing? With these questions lingering in the margins of what follows, I begin here with the recent, intense, and wide-ranging discussions of the nature of scientific truth. Within the social sciences these discussions have left a trail of misunderstandings, animosities, and an increasing divide between traditionalists and those variously termed "post-foundationalist," "post-empiricist," and "post-modern". It is not my intention to review the vast body of literature surrounding these issues, nor to resolve the remaining tensions. Rather, in what follows I shall first bring into focus what appear to be some of the most widely recognized outcomes of these debates often drawing support from both critics and defenders of tradition. With these in hand, I shall extend the logics implicit in these conclusions to explore an emergent conception of what it is to conduct research within the human or social sciences. Here I will point to significant shortcomings of widely shared traditions, both conceptual and pragmatic. I will then outline the potentials of what I see as a far more promising alternative. This conception of a future forming orientation to research opens the way to new aims, practices, ethical deliberations, and reflections. My intent in this case is not to eliminate the longstanding traditions, but to bring into focus new and far-reaching potentials of inquiry.

\section{The Emergence of a Reflective Pragmatism}

For over 50 years now social scientists have joined with scholars across the humanities and natural sciences in dialogue and debate on the extent to which our common practices of establishing knowledge embody the traditional ideals of objectivity and truth. Wide-ranging critiques based on the value saturation of knowledge claims, their literary and rhetorical dependency, and their social (as opposed to empirical) origins, have virtually eliminated the quest for a foundational philosophy of science. Called into question is nothing less than the legacy of the Enlightenment and the rational foundations of science. Yet, within the social sciences we find the vitriolic controversies of the so-called "science wars" have largely subsided. Putting aside those enclaves that simply remained oblivious, this mellowing may be traced both to a broad resistance (both conceptual and practical) to the extreme forms of critique and defense, and to a growing acceptance of some of the less nihilistic critiques. In effect there are several lines of critique that, in their less antagonistic form, have become relatively uncontroversial. Agreement on these assumptions does allow a place for traditional lines of research, although qualified in significant respects. I would characterize this emerging consensus as a reflective pragmatism (Gergen, 2014). Most important for the present undertaking, lying implicit within these assumptions is the rationale for a radical departure from traditional orientations to research. After describing the emerging position, I will take up the more challenging implications for research.

The two most widely shared assumptions lending themselves to a reflective pragmatism are as follows:

Whatever exists makes no necessary requirements on representation. One of the most contentious sticking points in the ongoing debates concerns the extent to which our accounts of the world can be driven or determined by events in the world. On the one side is the empiricist tradition, holding that descriptions of the world are "data driven," and can be corrected and improved through observation. On the other are numerous scholars from across the social sciences holding that without something akin to a theoretical (or linguistic) forestructure, there are no meaningful observations. In effect, theory determines what count as data. Putting side the extremities of these positions (e.g. naïve empiricism vs. linguistic 
reductionism), there is one way of phrasing the issue about which most social scientists would agree. That is, whatever we take to be the world does not demand or require any particular form of representation (e.g. utterances, markings, movements, signals, or graphics). At its most banal, this is simply to point out that there are many different ways to describe or otherwise represent whatever is before us. With Saussure (1916) it is to point to the culturally situated character of the relationships between signifier and signified. With Quineau (1981) it is to acknowledge the multiple ways one might describe what we might otherwise call "the same situation." More interestingly it is to propose (with Kant) that it is not only space and time that cannot be derived from experience, but indeed, that experience alone would not demand such common words as "desk" and "chair". A second conciliatory assumption follows the first.

What stands as objective truth can be established within a research tradition. A significant tension between traditionalists and their critics concerns the presumption that scientific research enables us to make progress toward objective truth. Traditionalists draw support from the manifest achievements of the physical sciences, while critics assail the traditional concepts "progress", "objectivity", and "truth". However, by recognizing the useful outcomes of the physical science research, combined with a relinquishing of the strong claims to foundations, a viable middle ground has been achieved. With the mutual understanding that the relationship between world and word is negotiable, there is broad accord that useful agreements can be reached on the character of what exists. Without philosophic justification, daily life effortlessly proceeds if we agree to index this as "an apple" and that as "an orange". More formally, Berger and Luckmann (1967) would say that the social order depends importantly on sedimented understandings. With Bourdieu's (1977) concept of the habitus, it is to recognize the common-sense structures of everyday life - including concepts, practices, and artifacts.

Most importantly, while the naming of the real cannot be justified through the act of reference, it is this very sedimentation of social understandings that permits the communities of science to achieve what we ordinarily view as progress. With Kuhn (1962), it is to say that once there is a shared paradigm (metaphysical, ontological, and practical), the sciences become productive. Only then can we split atoms, place a man on the moon, or eliminate smallpox. By the same token, it is possible for sociologists to make predictions about population shifts, economists to predict the effects of government policy on economic growth, or psychologists to predict the likelihood of criminal recidivism - all subject to falsification. This argument applies as well to the more interpretively based social sciences. While there may be no ultimate truth testing in hermeneutically informed inquiry, there can be relatively high levels of agreement within circumscribed enclaves about the character of subjective life. By the same token, within circumscribed traditions of understanding, it is possible to test hypotheses, or to write objective history, falsifiable ethnography, and accurate accounts of inter-group hostility.

With broad agreement in these two assumptions, the contentious atmosphere of recent decades has begun to subside. As Wertz (2011) has put it, there is an emerging a quite robust spirit of pluralism. We need not lose ourselves in the internecine combat over foundations, nor do we make claims to transcendent or God's eye truth. Rather, we can accept all forms of research - from laboratory experimentation to single case interpretation - in our work. It is indeed this spirit of pluralism that has fueled the enormous expansion in qualitative research practices. Denzin and Lincoln's pivotal volume, The handbook of qualitative research was first published in 1994. Yet, by casting aside the authority of foundations, the range of research methods burgeoned, such that by 2011 the work had gone through four new editions. As a result of these developments, few researchers now ask about the capacity of research to yield socially uninflected truth. Rather, reflection moves from issues of philosophic grounding to social utility. Because all research practices can be legitimated in their own terms, the question then becomes one of outcomes. What does the research ultimately contribute to the world more generally? And this question is accompanied by a critical concern with politics and ideology. For whom are the outcomes useful, and in what way; who is benefited, who may be harmed; and who is absent from the discussion? We have, then, a 
pragmatism with a social conscience.

There is much to be said in favor of this condition of relative accord. However, lingering in the wings, there is a dulling sense of the eternal return of the same. Traditional practices of research remain unchallenged; and while there is an impressive accretion in the range of practices, they do little to violate or challenge the basic structure of inquiry. Most important for present purposes, this condition of reflective pragmatism sustains an ocularcentric conception of knowledge (Levin, 1993; Kavanagh, 2004). That is, the vast share of these research practices carry with them a dualist premise, distinguishing between the world on the one side and the observer on the other. The process of observation is essentially visual as opposed, for example, to tactile or auditory. Metaphorically, then, the process of research is effectively one of watching, looking, or seeing. As Rorty (1979) and others have characterized the process, the mind of the researcher ideally functions as a mirror of nature. The traditional means of safeguarding research from bias -inter-observer reliability, double-blind methodologies, standardized questions, large samples, and the like - thus function to "cleanse the mirror". In this metaphorical vein, we may characterize the researcher as a mirror holder. As an instrument, the researcher cleans the mirror and holds it steady so that it may function without interference.

I am not proposing that there is broad acceptance of the metaphor itself; indeed it has been the subject of significant critique. However, as debates over the grounds of inquiry are abandoned in favor of a pluralist pragmatics, the traditional form of research remains largely unchallenged. While the metaphor is no longer commanding, its vestiges remain solid. Thus, the vast share of research today remains dedicated to "revealing," "illuminating," "understanding," or "reflecting," a given states of affairs. To sample across a wide spectrum, we are variously informed, that "this research tests the proposition that..." (Koenig \& Eagly, 2014), "These findings provide preliminary evidence for ...” (Scott \& Weems, 2013), “This research examined how..." (Ingrids, 2014), and "The purpose of this study is to explore the experience of..." (McDonald, Pietsch, \& Wilson, 2010). In my view, this ocularcentric tradition severely constrains the capacities of the social sciences. Further, if we extend the implications of the assumptions previously described, we can locate a radically new vision of research and its potentials.

\section{Constatives, Performatives, and Consequences}

In his groundbreaking work, How to do things with words, J.L. Austin (1962) drew the famous distinction between constative and performative utterances. The former refer to statements of fact, essentially falsifiable through observation (e.g. The cat is on the mat.), and the latter to statements that in themselves bring about changes in existing states of affairs (e.g. Run for your life!) Austen was himself quick to illuminate the impurities of the distinction, a point on which many philosophers and literary theorists have since expanded. Most important for present purposes, many scholars - including Austen himself - points to the possibility that all constatives - at least by implication - can be understood as performative. This possibility is most clearly applicable to the social sciences. In a classic illustration of a performative: "I name this ship "the Queen Elizabeth'," the act of naming has consequences for subsequent actions. In the same way, as social scientists go about describing the nature of "aggression," "mental illness," "suicide," and the like, they are "naming" or "dubbing" those under study in ways that invite our actions toward them - curtailing their aggression, treating mental illness, preventing suicide, and so on. Such consequences were indeed the focus of early "labeling" studies of social deviance (see, for example, Gove, 1975)

Nor is this consequential character of social science description limited only to value saturated language, such as the above. As Peter Winch (1958) once wrote, "Since understanding something involves understanding its contradiction, someone who, with understanding, performs X must be capable of envisioning the possibility of doing not X"(p. 89). By implication, this is to say that any research that purports to describe human behavior, also establishes the grounds for possible action (or resistance). To 
know about a given form of behavior, is to envision the possibility of its being done (or not). Thus, to learn about the range of sexual practices in which people engage (Szuchman \& Muscarella, 2000) is to open new options for one's own activities; to read an historical account of the cultural basis for a mother's love for her offspring (Badinter, 1981) is to free mothers of guilt for moments of indifference to their own children.

In certain respects the point I am making fits congenially into the account of reflective pragmatism outlined above. Constative utterances are essential within any scientific community to carry out their activities. In this sense, they have important pragmatic value and simultaneously sustain the shared values of the community. What is added here is the way in which these "reality-posits" and their attendant values play out as they are shared with the culture more broadly. In effect, in their descriptions of human activity, communities of social science have the capacity to transform the society more generally.

These proposals are foreshadowed in earlier writing, both my own (Gergen, 1973) and that of Ian Hacking (2000). In my earlier work I discussed the difficulty of separating description from prescription in social psychology, and described what I called enlightenment effects to account for the way in which exposure to scientists' accounts of social behavior could alter patterns of behavior in society. Because the conduct of science can transform its subject matter, I argued, social psychology is not so much an accumulative or progressive science as it is historical. Hacking (2000) later referred to looping effects to account for the way in which morally saturated descriptors in the social science can alter social understanding and resulting patterns of cultural life. Yet, in these writings, neither Hacking nor I move beyond critical analysis. For both of us the outcome was that of situating social science knowledge in historical context. We failed to explore the productive possibilities.

In what follows I wish to expand the implications of these enlightenment or looping effects to develop a more pro-active vision of the potentials for social science inquiry. Rather than acknowledging such effects in the service of a more reflective view of the sciences, a case will be made for research as a future forming practice - a practice in which social change is indeed the primary goal. Before exploring the potentials of this view, it is useful to underscore the limits and dangers of research as mirror.

\section{The Captivating Gaze}

As proposed, if there is local agreement among researchers in a descriptive or interpretive language, along with referential practices and methodological procedures, researchers may indeed contribute to the community of which they are a part. And if there is a public that shares in these agreements, they too may find benefit in the outcomes of research. Thus, with agreements in place, research on economic outcomes, migration trajectories, and the evaluation of healthcare programs, for example, could have significant social utility. Similarly, under conditions of common accord, narrative research can illuminate the suffering of the oppressed, phenomenology can give us insight into the experience of loneliness, and conversation analysis can give us insights into the structure of conversation. Practically speaking, we should not dispense with the tradition. At the same time, there are inimical consequences for both the human sciences and the societies they serve. Shared agreements are essentially captivating. And in significant degree, the captivating gaze simultaneously constrains the imagination and numbs the sensitivity to consequences.

At the outset, the very agreements essential to moving forward with a research endeavor are, in effect, ontologically and culturally preserving. That is, they sustain existing traditions of indexing the world along with the forms of life in which they are embedded. One may comfortably launch research into the causes of prejudice, aggression, human happiness, aging, and so on because these are commonly shared terms for understanding the world. One could scarcely locate support for research on liget or chan because within the West, such terms are culturally opaque. To illuminate, reflect, or understand a given 
state of affairs, sustains a tradition in which this "state of affairs" has acquired ontological status. Or, one might say, in conducting research on what exists, we lend inertia to conventional forms of life. We do not readily ask about what does not yet exist, or about ways of life that could be created. In effect, the mirroring tradition of research favors the maintenance of the status quo.

These same limits to the imagination also interfere with the researcher's understanding of research consequences. Here my concern is with the enlightenment or looping effects of inquiry on the society at large. How, for example, does research on the neural basis of altruism, on the trajectory of grief, or the positive consequences of optimism affect the logics and patterns of cultural life? As researchers concretize a given reality - along with concomitant values and forms of action - they are ill prepared to explore or appreciate points of view that challenge the ontology. It would be difficult for researchers focused on the decline of mental abilities with aging to embrace a theory of aging as a period of growth and development, or for researchers on child abuse to tolerate the opinions of the Man/Boy Love Association. Perhaps the most striking example of this intransigence is furnished by research into mental illness. In the late 1930s the newly emerging psychiatric profession shared a nosology of some 40 terms for diagnosing mental illness, and the healthcare costs for mentally illness were unremarkable. With the advanced visibility of the profession and with government supported efforts to expand public consciousness, by 1950 there were 1.6 million patient-care episodes. Categories of mental illness continued to increase, and by 2000 there were some 350 ways of defining oneself as mentally ill. The number of patient-care episodes jumped to 10.7 million (Whitaker, 2010). With additional support from the pharmaceutical industry, mental illness expenditures now compete with heart disease and cancer. Yet, in spite of intensive critique of diagnostics and pharmaceutical "cures" from across the professional and public spectrum, the psychiatric profession has continued its efforts without pause. Mental illness is, after all, an object of scientific research. And thus the gaze solidifies its object.

\section{From Mirroring to Making}

Given the limits of the mirroring metaphor of research, I return to the issue of consequences. As I have proposed, when research commences with an "object of study" the result is an extension of existing traditions, and suppression of alternative realities. The social imaginary is circumscribed. But, we may ask, what if we suspended the mirror metaphor, and its invitation to study that which captivates the gaze? Metaphorically speaking, what if we closed our eyes and began to imagine the worlds of our hopes? What if we replaced the persistent rush to establish "what is the case" and began to ask, "what kind of world could we build"? This would be to place the researcher's values in the forefront of his/her activities. Rather than their latent presence in the choice of terminology and methodology, and in the vain hopes that an absent audience will somehow make use of one's work, what if purposeful and passionate visions supplied the source of inquiry? Given a valued vision of the possible, the challenge for research would be to explore how such a possibility could be realized. The aim of research would not be to illuminate what is, but to create what is to become. Herein lies the essence of a future forming orientation to research.

There are resonances here with a rich array of existing ideas. In a certain sense, this is to extend the Aristotelian concept of knowledge through praxis. Where the pursuit of knowledge through theoria is to establish an articulated truth, knowledge through praxis is achieved through and represented within ongoing action. In contemporary educational circles the distinction is represented in the contrast between propositional and procedural knowledge, where the latter is implicit, unformalized, and realized through accomplishment. Also relevant is the Socratic concept of episteme, or knowledge embedded in the active accomplishment of a goal, with techne representing the craft-like ability to make or perform. In a slightly different register, Arendt's (1958) critique of philosophy as unduly contemplative (vita contemplativa), and thus withdrawn from human affairs, is relevant. As she hoped, philosophy could become more fully 
engaged in projects of social change. For her, it is in this active engagement (vita activa) that human freedom is most fully realized. Relevant as well is Friere's (1970) critique of the oppressive impact of established knowledge, and the importance of a liberatory education. The latter would largely be realized in embodied action. More recently, we may draw from Ingold's (2011) characterization of life in terms of continuous becoming, a conception in which our major challenges are found within the emerging and ever shifting conditions of moment-to-moment existence.

How should research be constituted in this future forming orientation? I shall later explore the possibilities more fully. However, as a preparatory spur, I return to classic research by developmental psychologist Harry Harlow. In his early studies Harlow and his colleagues (Harlow, Dodsworth and Harlow, 1965) demonstrated that macaque monkeys reared in social isolation for six months suffered severe deficits in every aspect of their subsequent behavior with other monkeys. This research was consistent with a broad literature on infant attachment, and was widely used to celebrate a biological account of attachment needs. In effect, the research functioned to mirror the common conceptions of infant development. Later, however, Harlow and Suomi (1971) challenged this nomothetically based inquiry by wondering if they might find a way to reverse these seemingly permanent deficits. Ultimately they discovered that if they allowed the six-month isolates to play freely with a three-month-old normal monkey, they could eliminate the effects of isolation. The research orientation effectively shifted from the given to the imaginary, and with significant results.

By the same token, rather than demonstrating humankind's common failings in cognitive processing (Kahneman, Slovic and Twersky, 1982), what if research were directed to erasing the biases; rather than searching for the determinants of depression (Altemus, 2006), inquiry were launched into means of escaping or avoiding depression; rather than revealing the suffering experienced by immigrants (Sayad, 2004), inquiry were directed to advancing immigrant well-being; rather than focusing on the way discourse functions to foster "otherness" (Tekin, 2010), the emphasis were placed on how discourse can be used to foster mutuality; and, rather than documenting the many failings attributed to age (Mani, Bedwell, and Miller, 2005), researchers explored ways to stimulate late-life flowering? More broadly, rather than illuminating the corrosive effects of poverty, researchers attempted to develop job programs; rather than documenting the persistence of hunger, the sciences set out to eradicate hunger; rather than focusing on the causes war, scientists joined in erecting impediments to war.

I shall shortly expand on the contours of future forming research. Before doing so, however, there are two preliminary matters of importance. The first concerns metaphysical assumptions and the second contemporary world conditions, both of which add substantial weight to the present proposal.

\section{Social Research in Metaphysical Context}

All inquiry is informed either directly or indirectly by certain assumptions or enabling agreements, whether in the form a metaphysical background or fully articulated ontologies. It is to these metaphysical underpinnings that I direct attention in this case, as the shift from mirroring to making presages what could be understood as a profound shift in the conception of knowledge. If fully expanded, this shift would carry with it equally significant implications for social science inquiry. As we have come to understand scientific knowledge, its goal is to illuminate a subject matter in such a way that its outcomes will benefit future action. Traditionally this benefit is couched in the language of prediction and control, but in a less pronounced way may be found in all mirroring research. But what must be assumed about the nature of this subject matter to render such a goal plausible? At least one characteristic would seem to be the character of endurance. That is, the subject matter must be sufficiently enduring (repetitive or replicable) that useful knowledge can be established. When we can presume the enduring existence of a subject matter, we can properly begin to measure, generalize, and predict. The very concept of research enshrines 
the assumption, suggesting that the object of our gaze remains stable, such that we can return to "search" again. In re/search, assumptions about the subject matter can be vindicated or vanquished, and useful generalizations or insights may be shared.

In significant respects this assumption of perdurance represents a continuation of a metaphysical tradition with origins in early Greek philosophy, and most especially in the works of Aristotle and Plato. Both sought to justify a belief in a cosmos of permanent or substantial forms. For Plato the forms exist as pure ideals; for Aristotle the substantial forms serve to organize matter such that it has recognizable properties. On this view, knowledge may endure or be accumulated over time. Yet, one may also see these views as attempts to answer questions implicit in an earlier metaphysics of impermanence. This metaphysics is most centrally attributed to Heraclitus. For Heraclitus, "Everything changes and nothing remains still." On this account, however, the possibility of accumulating knowledge is dim. Recognizing the sensory or empirical justification for the Heracletian view, the challenge was to develop a more reassuring alternative; thus a metaphysics of an essence somewhere behind or beyond the empirically evident. There are many reasons for the flourishing of the Aristotelian and Platonic metaphysics in Western history, not only in terms of its supportive role in Christian theology, but as justification for a vision of science as a cumulative undertaking. It is not until the nineteenth century - in the work of Hegel (1832) and Bergson (1911) - among others, that there was a significant re-emergence of interest in process, possibly culminating in Whitehead's 1929 work, Process and reality.

While attempts to justify a given metaphysics are ultimately doomed to an infinite regress of justification, it is useful to address the question of pragmatic potentials. If the presumption of permanence is optional, what is gained or lost in the social sciences by sustaining its embrace? Concomitantly, what are the potential consequences of a metaphysics of change? As I am proposing, the limitations in the traditional orientation are substantial; the potentials of a process-oriented metaphysics are rich and largely unexplored. In this light, it is useful to consider what appear to be our contemporary world conditions.

\section{Research in a World of Flux}

It is perhaps a signal of the times that anthropologists find it increasingly difficult to locate stable, geographically isolated cultures for ethnographic research. Rather, attentions turn increasingly to global flows, dispersions, transient sub-cultures, and identity conflicts (Clifford, 1997; Appadurai, 2001). As one might say, the traditional "objects of study" are slowly dissolving. Is it possible, we may ask, that this is the coming condition for all the social sciences? In light of the impact of communication technologies on cultural life, such a conclusion seems eminently plausible. For roughly a century we have seen the flourishing of technologies that intensify, complexify, and accelerate the processes of communication. Beginning with the radio, the automobile, mass transportation systems, and mass publishing in early twentieth century, and subsequently adding jet transportation, television, the internet, and the cell phone, the landscape of human interchange is radically altered. All such technologies function to create, sustain, or subvert forms of understanding or belief, with the result that worlds of meaning are in continuous motion - with modifications, absorptions, clashes, and creations occurring incessantly and instantaneously around the globe. If human action is significantly dependent on negotiated agreements among people, as suggested earlier, then stable traditions are everywhere under siege.

Such shifts in world conditions have been the subject of wide-ranging scholarly concern. Berman's (1983), All that is solid melts into air: The experience of modernity, and Hardison's (1990) Disappearing through the skylight: Culture and technology in the twentieth century, were bell-weathers. My own work, The saturated self: Dilemmas of identity in everyday life, subsequently focused on the impact of technology on conceptions of self. And in more recent times, there are, for example, the works of Eitzen and Zinn (2011) on changes in society resulting from massive globalization; Rogers (2011) on 
the "age of fracture"; Bauman (2011) on the emerging "liquidity" of human relationships, and Giddens (2000) on the way globalization is reshaping our lives. These are, of course, working propositions, but they pose a formidable question. If we find ourselves in a world where increasingly unpredictable fluctuation marks every facet of life - from self-conception, family life, and community to global configurations of power, economy, and illness - what is the place of a research tradition that attempts to mirror a stable state of affairs? In what sense can we sustain an assumption of progress in knowledge? As I am proposing, the more promising vista lies in a science that engages in the very shaping of the directions of change.

\section{Toward Future Forming Research}

We move now to consider the contours of research from a future forming perspective. In my view the most productive route in this case is not to embark on a disjunctive, imaginary world- a world of inquiry beyond the reach of contemporary researchers. Rather, it would seem more promising to examine current and emerging practices with future forming potential. If such practices can be illuminated in terms of this potential, a new consciousness may be germinated. New and more potent practices may be stimulated. In certain respects, then, the present offering may serve as a mid-wife to a movement in the making. A voice may be given to an otherwise unarticulated sensibility, thus giving form and function to future undertakings. In this light, I wish to consider three forms of inquiry with prescient potential.

\section{Inquiry as Incitement}

Emerging in the 1930's, the critical movement in the social sciences has now spawned multiple sites of activity across the disciplines. One might well see this work as tissued to the Enlightenment tradition of truth seeking. For example, the empiricist's truth claims might be pitted against those of the critical realist in terms of "getting it right" about the world. However, there are more subtle ways in which the critical movement lends itself to the future forming vision developed here. As outlined in the earlier discussion of consequential constatives, and reflected more fully in the liberatory movement more generally (MartinBaro, 1994; Watkins \& Shulman, 2010), the attempt is to draw critical attention to existing ways of life, and to engender a critical consciousness from which social change might spring. The hope is that "seeing with new eyes" can incite resistance to the status quo.

While the greatest share of critical work today is arguably theoretical, there is wide ranging research devoted to liberatory ends. The methodological options for doing such work are unbounded. Even laboratory experimentation has been used for such purposes. Both the classic work of Asch (1956) and Milgram (1963) had far less to do with hypothesis testing, as it informed generations of students of the dangers of conformity and obedience. However, today one of the most well developed forms of research is critical discourse analysis. Here the intention is to illuminate forms of language use that variously serve to oppress, discriminate, dominate, or function in other socially corrosive ways. Inspired especially by liberatory ideas, the goal of such research is to free the reader from traditional or common-sense ways of constructing the world. For example, Coates (2013) illuminates the way group prejudices are normalized in everyday discourse on heterosexuality; Simpson and Mayr (2010) showcase the various ways in which language is used to generate power differences; and Breeze (2012) demonstrates the rhetorical strategies by which corporations legitimate their malfeasance. Willig's (1999) edited volume, Applied discourse analysis, features critical analyses of the taken-for-granted assumptions in self-help literature, reproductive technologies, psychiatric medication, and sex education.

Yet, there are also substantial limits to critical research in its future forming potentials. Although challenging the status quo, the tradition has done far less to fertilize visionary potentials. The critical skills 
are well honed, but the imaginary register is seldom explored. There are several unfortunate outcomes. On the one side, critical work typically discredits its targets (the powerful, colonialists, men, psychiatrists). While inciting resistance, the pejorative rhetoric galvanizes its opposition and lends itself to increased polarization. Further, the potential audience for critical work can too easily predict the outcomes. The likelihood of finding in such work a balanced weighing of competing views is slim. Critical scholars have also turned their weapons on each other (e.g. realists vs. constructionists, feminist factionalism, the gender blindness of Marxism). And, while not a principled limitation, most critical research is also limited to academic journals and monographs. The rhetorical genres inherent in these traditions, are either wearisome or impenetrable to the public at large. Too often, critique remains hermetically distanced from the surrounding culture.

In this latter light, there is considerable promise to be found in the performative movement in social science (see Gergen \& Gergen, 2012). Much of this work is lodged in the premise discussed earlier, that whatever there is makes no necessary demands on the language of representation. In this light, questions open as to the necessity of using traditional genres of scientific writing. Here critics weigh in on the failure of academic writing to be understood or appreciated by the greater public. As often voiced, such writing is elitist, and serves only to increase the power of those who are privileged by virtue of education and class. The performative orientation opens the way to exploring multiple forms of writing, including for example the use of short stories, poetry, autobiography, collaborative writing, and more. Other researchers explore the potentials of representation beyond writing. As it is argued, why not enable the social sciences to make use of the full range of communicative acts, including theater, art, music, photography, multimedia, and more. Critical researchers in the performative domain are thus advantaged by a powerful array of rhetorical means by which they can reach a larger public with far greater impact. For example, researchers have variously performed what it is like to "come out" as a homosexual (Saldaña, 2011), to be ostracized as an aging woman (Gergen, M., 2012), or to be dehumanized in receiving treatment for metastasized cancer (Gray \& Sinding, 2002). Yet, even in expanding on the future forming potentials of inquiry, performative work is limited. Audiences are generally small - often restricted to academic gatherings. And, while entertained, enlightened, or moved within the space of the performance, one can only conjecture about the resulting outcomes in action.

\section{Research as Creative Construction}

A more pronounced step toward developing future-altering research is represented by a disparate range of researchers attempting to build or create new "forms of life." Embracing more fully a vision of knowledge through praxis, they set out to create replicable practices that achieve value-invested goals. The aim is not to illuminate existing problems in society, but to devise practices that can achieve better or more viable outcomes. Such an orientation has been especially appealing in fields specifically confronted with practical challenges (e.g. education, organizational development, health-care, mental health, conflict reduction). In many of these domains the traditional attempt to solve problems through scientific research has been frustrating or ineffective. Traditional research is often dedicated to substantiating theoretical propositions; however, there is no obvious means of deriving from abstract propositions actions relevant to specific circumstances. Even when research is designed to solve a particular problem, it is troubled by the narrow range of selected variables, ambiguities in measurement, conflicts among statistical models, and multiple interpretations of findings, all in a context of continuously fluctuating conditions. Traditional research yields no trustworthy or commanding path to the future. The result among practitioners is an increasing sense that "The best way to predict the future is to create it."

A dramatic illustration of this orientation is provided by scholars at Case Western Reserve. Drawing from narrative and constructionist ideas, they created an alternative to traditional practices of 
scientific management. The tradition of gathering systematic data on organizational functioning, from which executives should derive optimal decisions, had always been precarious. In this contrasting orientation, organizational participants collectively determine the optimal course of organizational development (Cooperrider \& Whitney, 2005). This practice, called appreciative inquiry, first gives expression to the individual stories of organizational participants, and from these expressions, locates common values. From these values, new directions for the organization are derived, and new policies and practices put in place. To illustrate, in an organization in which there is disabling conflict (e.g union vs. management, males vs. females), participants from each side of the conflict may be paired off, and invited to share stories of a time in which they worked together amicably and productively. The pairs then join larger groups, in which they share the best of the stories. This sharing replaces the discourse of mutual blame, and generates confidence that a better future may be created. From this sharing the groups locate visions of ideal relationships, from which they derive policies and practices that would realize these ideals. The stage is then set for putting the plans and practices in motion. "Problem talk" is replaced by dialogue with an appreciative focus. Practices of appreciative inquiry have proved so effective that they have now been used by major corporations, national governments (to generate a new constitution in Nepal), groups attempting to create a United Religions organization (paralleling the United Nations), along with countless local groups - large and small - throughout the world. This orientation to decision making is now heralded as the "new wave" in organizational development (Marshak \& Grant, 2008).

This more pro-active approach to research can be found in many other practice oriented fields of inquiry. For example, confronted with an increasing volume of hospitalized psychiatric patients and pharmaceutical prescriptions, an innovative group in Finland (Seikkula \& Arnkil, 2006) decided to abandon the traditional psychiatric evaluation procedure. In its place they created a practice called open dialogue. Rather than relying on the single diagnosis of a psychiatrist - which would ultimately require defining the problem in terms of a mental illness - open meetings were arranged in which a range of stakeholders could participate. This might include, for example, a psychiatrist, parents, a social worker, a teacher, a clergy member and the "designated patient". All would join in discussing the nature of the problem and possible forms of alleviation. This dialogue group would continue to meet during the treatment process. The result was a dramatic decrease in the number of hospital beds occupied and reliance on pharmaceuticals. In the field of health-care, the work of Charon (2008) and others has responded to critiques of medical interviewing, in which the patient is so often treated instrumentally - as a mere object to be diagnosed and treated by scientific means. As an alternative, new practices of medical evaluation were created in which patients share their personal lives (life narratives), a practice resulting in a more caring and clinically sensitive relationships between doctor and patient. In the field of conflict resolution, scholars have pressed forward to build a variety of new practices. In the case of the highly successful public conversations project (Herzig \& Chasin, 2005), for example, a form of conversation was crafted that enables participants to express their convictions in a way that could be more sympathetically absorbed by their opponents. This conversational practice has been used to quell otherwise intense conflicts on abortion rights, gun rights, homosexuality, religion, and more.

In all these domains, we have a form of research in which knowledge is acquired through the complex and creative process of constructing a successful practice (see also Hassan, 2014; and Kahane 2012). When such knowledge is shared, it becomes a resource for others. There is also a manner in which such research is cumulative. As multiple practices are generated, they provide alternatives from which one can select as best fits local needs (see, for example, Bojer, Roehl, \& Knuth, 2008), or from which new hybrids can be formed. A collation of practices on peace building, for example, provides what amounts to a "vocabulary" from which new practices can emerge.

\section{Research as Collaborative Action}


The potentials of inquiry into future building practices are enormous. However, one limitation of this genre lies in the fact that the capacity for creation remains primarily in the hands of the research community. Would it be possible, one asks, to enhance the potential of the populace to experiment more creatively in developing alternatives to unwanted conditions? This is all the more important because the efficacy of newly developed practices is indeterminate. For example, with constant repetition, the meaning of dialogue can shift; conversations once absorbing in their spontaneity now become programmatic and subject to strategizing. This is especially relevant, for example, to peace building practices. Knowledge of a dialogic practice renders it subject to manipulation.

One highly promising alternative to practice building is represented in the attempt of an increasing range of researchers to work collaboratively with those outside the academy in achieving social change. More formally, such efforts are termed action research. Although early action research was largely confined to issues of social justice, within the past decade the scope and variations have significantly escalated (see Reason \& Bradbury, 2008). Much of this work shares in a conception of practice based - as opposed to propositional - knowing, as discussed earlier. Most interesting, however, is a shift within the action research community from a conception of knowledge as an individual possession, to knowledge as inhering within relations among people. On this account, the coordinated activities of persons bring about what may be viewed as an organization that thinks, learns, or processes information (see for example, Salomon, 1997; Engestrom, 2010). It is in this context that many organizational scholars share an interest in communities of practice, and especially relevant to the present offering, learning communities

This is not the context for a broad review of the many forms and sites of action research. However, a brief scanning of cases can illustrate the potentials of research in the service of future forming. As mentioned, much action research has been used in the service of social justice. Thus, researchers have joined with women in prison to gain their rights (Fine \& Torres, 2006), organized innovative resistance to anti-gay legislation (Russell \& Bohan, 1999), and worked with organizations to develop participatory democracy (Karlsson, 1969). Other researchers have expanded the scope of action research to include the enhancement of community well-being. For example, Lykes (2001) has worked with Guatemalan women to help them build community after debilitating conflict, and UNICEF has initiated action research to develop communication strategies for preventing HIV/AIDS among adolescents in Bosnia Herzegovina (Maglajlic \& Tiffany, 2006).

Various professional fields have also launched collaborative action initiatives. In the field of education, for example, teachers are learning how to view their classroom as laboratories for participatory research (Wamba, 2011). In medicine, action research has been used in a variety of settings, to improve healthcare, create collaborative relations among staff, and improve understanding of patients (Waterman, et al. 2001). In the field of management, researchers are working with large companies to foster collaborative inquiry. In one major undertaking, for example, researchers collaborated with an agency in the US government, employing over 200,000 people, to successfully reduce workplace stress (Kowalski et $a l, 2003)$. In more expansive work, action research initiatives are being used to bring entire regions or countries into collaborative inquiry. Much of this work has involved creating dialogic connections among large institutions of business, education, and government for purposes of broad development (Gustafson, Finne and Oscarrson, 2001).

These three registers of inquiry - liberatory, practice producing, and action centered - illustrate the substantial potentials inherent in a future making orientation to research. In my view they carry with them the early winds of change, harbingers of a significant transformation in the conception of knowledge and the practice of social research. Now invited is a further exercise of the imagination, extending and expanding the vision of inquiry. There are promising possibilities, for example, in linking researchers with the creativity by design movement in the technological sphere. More broadly, one might explore the 
possibility of researchers working with governments to experiment with new and more viable forms of governance? Or, might it profit the world to have at its disposal a body of researchers whose talents were available to work creatively with conflicted parties? With education in the science of world making, and the broad dissemination of successful innovations, perhaps we could escape the logic of determinism and begin to realize the potential of collaboratively fashioning the future.

There are also important socio-political implications in this shift toward inquiry as future making. One of the major problems with the mirroring tradition is that conclusions about existing conditions have little impact on societal well-being. This is not only because the forms of discourse shared within the professions are largely unavailable or inaccessible to those outside, but the truth posits of the profession are highly vulnerable to critique on methodological grounds. The laboratory situations created for "testing" general hypotheses are typically remote from everyday life. The samples used in Western social science are often faulted as WEIRD (biased in terms of the Western, educated, industrialized, rich, and democratic samples). On the level of policy making, politicians are free to select from the available findings as fits their purposes. Conservative politicians often dismiss social science research altogether because of what they properly see as liberal bias. Others find traditional research results insensitive to the currents of social change; as it is said, social science research is "journalism in slow motion." In contrast, the significance of a future forming orientation to inquiry doesn't rest on generalized truth posits, so much as active achievements. That one could demonstrate a means for reducing a local conflict between police and the citizenry, coordinating the activities of a hospital staff, enabling an urban community to reduce crime, reducing pathological symptoms without pharmaceuticals, or reducing suicide through new technologies, would represent the fruits of inquiry. Nor does such research depend for its importance on the dynamics of political life. Social research in a future forming mode unsettles the structure of political power. Researchers themselves become agents of social change.

\section{Theory in a World of Change}

The present offering has almost exclusively focused on practices of research as opposed to theoretical work in the social sciences. Of course, one might argue that theoretical work is itself a form of research, but for present purposes it is useful to honor the traditional theory/research distinction. And too, all research carries with it premises or assumptions that may be viewed as theoretical. At the same time, there are scholarly enclaves across the social sciences primarily devoted to scholarly deliberation, and in which active research of the traditional sort is virtually absent. Before concluding the present paper, a brief reflection on the potentials of theoretical inquiry is useful.

At the outset, we can distinguish between the function of theory within the traditional vision of a mirroring science, and its potentials within the future making register. The chief functions of theory in traditional social science are primarily to integrate and synthesize findings, observations and interpretations from the broad domain of research; to provide a framework from which to mount fresh inquiry (bearing on the ultimate viability or truth value of the theory); and to offer the society an account of the world from which useful applications can be derived. Iconic here are Darwin's theory of evolution, Einstein's relativity theory, and Watson, Crick, and Maurice's double helix. Whether such a view is conceptually adequate, or the degree to which is it applicable to the social sciences are questions of longstanding debate. Most important here, however, is the question of how such an approach to theory functions in terms of its future making potentials.

There is no simple answer to this question, and for several reasons. Within the social sciences the presence of research findings has seldom served as a major impetus for theoretical conjecture. Although observations play a role in the classic theoretical works of Durkheim, Mead, Freud, Piaget, or Parsons, for example, there is little reliance on systematic research. Indeed, most such theories function as foundational 
statements about the nature of human action. Although more limited in scope, much the same can said of more recent theorists, such as Garfinkel, Goffman, Bruner, Harré, Honneth, and Maffesoli. As a result of this relative independence from what might otherwise be considered "established fact," the theorist is less constrained by commonly shared assumptions about social life. This liberation from the sedimented realities grants the theorist liberty to construct new and challenging intelligibilities. In my opinion, to the extent that such intelligibilties have inspired research in the social sciences, the outcome for society has been modest. This is largely owing to the above discussed separation of the research community from the society at large. At the same time, however, there is a large range of professions -education, mental health, social work, organizational consulting - hungry for orienting ideas and often eager for new ideas from which they may draw advantage. The work of these more imaginative theorists thus finds fertile ground. Thus for example, in Piaget and Inhelder's (1969) work, we find a significant impact on educational practices; Luhmann's (1996) systems theory and subsequent complexity theory are reflected in organizational development practices; Foucault's writing (1979) has had a significant impact on therapeutic practices. In effect, such theoretical formulations may significantly affect society without any reliance on traditional practices of verification/falsification.

Yet, in terms of future forming potential, it is unlikely that most of these theorists set out to alter the course of social life. While influential, the effects were more often inadvertent. What possibilities are open, then, when the theorist indeed intends to use his/her work to affect society? Certainly Marxist theory - in its heady mixture of description and prescription - represents a beacon in this respect. Critical theory, feminist theory, and post-colonial theory all carry the revolutionary traces of the Marxist movement. The extent to which such theory is successful in escaping the confines of academia remains open to debate. Recent attempts to change individualist ideology have been coupled with developments in relational theory (Gergen, 2009; Kirschner \& Martin, 2010). Here theorists attempt to replace the traditional understanding of society as constituted by individual units or persons, with a vision of relational process from which the very idea of individual persons may (or not) emerge. Relational theory now moves slowly into practices of education, therapy and organizational development. In sum, in future deliberations on the possibility of a future making science, social theorists must be given a significant seat at the table.

\section{Concluding Challenges}

The proposed vision of the researcher as an active agent in fashioning the future raises many questions, both conceptual and practical. On the conceptual side, there remains the challenge of more fully enriching the conception of knowledge from a process standpoint. As we have seen, there are promising fragments available, from early Greek philosophy to the present. And one can generate a plausible case for a form of process knowledge that focuses on the ways in the continuous engagement in action fashions one's future undertakings. More radically, the way is open to refiguring what we are calling propositional knowledge as a limited form of process knowledge. "Knowing that" may be viewed as a specialized form of "knowing how," with claims to the former masking their dependency on the unarticulated process from which they derive. However, a more adequate account of the terrain would do much to give form and direction to the kinds of endeavors treated here. Closely related is the concept of education, commonly viewed as the transmission of knowledge from one generation to the next. One might justifiably argue that the traditional focus on the mastery of existing knowledge is relatively ineffectual; after all, one's recall of long-ago lessons is notoriously unreliable. More importantly, in a world of rapid and unpredictable flux, the focus on what is the case has limited potential. The challenge is that of rapidly synthesizing multiple sources of information, and moving improvisationally in a context of ambiguity. Required is a more fully developed account of education as a continuous enrichment in capacities for skillful innovation, not in the service of adaptation, but in terms of bringing about a viable future. 
At the same time, I see within the future forming frame, a renewal and re/visioning of the moral dimension of inquiry. Most researchers within the mirroring tradition escape significant deliberation of such issues, with the claim that the rigorous illumination of what is the case will somehow benefit the world. While critical theorists have provided teeming illustrations of the ideological saturation of social research, and others have continued to enrich our understanding of the moral dimensions of social inquiry (e.g. Richardson, Fowers, and Guignon, 1999; Brinkmann, 2011), the relevant research communities seem unaffected. Most research traditions continue with little reflection on their ideological or moral implications. However, if the vision of research as a future forming endeavor is more fully realized, there is little escaping deliberation on such issues. This is so because in specifying those future conditions to which one's efforts are dedicated, one is fundamentally addressing issues of value. To responsibly address the question of "to what kind of future can I contribute," is to face complex questions of the good. "For whom would such an achievement be valuable; for whom would it be oppressive; what are we to do with multiple traditions of the good?" The traditional claim that science is concerned with what is, rather than what ought to be, is now reversed.

In my view, the logic developed in the present offering would also add significant dimension to such deliberations. Issues of moral choice are traditionally linked to the individual actor. It is the individual who acquires moral worth by virtue of his/her choices. There are close associations between this view and the ocularist tradition in science. The metaphor of the lone figure of Galileo heroically confronting the church, lends tacit support to an individualist view of moral decision-making. The question of "ought" is thus a personal one: "what future do I value?" However, there is an important way in which the logic developed here shifts the site of moral choice from the individual to the relational sphere. The key point is embedded in the earlier proposition that to know about a given form of behavior opens the possibility of its being done (or not). Inhering in this view is an understanding of human action as issuing from shared intelligibilities. By and large, we go about our lives in ways that "make sense" within the relations in which we participate - simultaneously reflecting and potentially transforming tradition. From this standpoint, activities become valuable, worthwhile, or moral from within relational activity. Whether it is devoting oneself to video games or to martyrdom, the origins of action lie within the realm of relationships. It follows from this position that one cannot principally ask about the value of one's research as a moral atom, a lone decision maker. What pass for individual decisions are essentially social actions removed from their birthplace in the swarm.

That moral proclivities have their roots in social traditions is scarcely a new idea (MacIntyre, 1981; Alexander, 2002). However, the implications for deliberating on the outcomes of research do take a new turn. We live in a world of competing and conflicting moral traditions. The values represented in any research endeavor are inherently vulnerable. It is insufficient, then, to rest the case for one's inquiry on a single moral tradition. When this tradition is set against all others, the stage is set for an interminable conflict of principles. And as contemporary world conditions attest, such conflict is lethal in consequence. As we find, a multiplication of goods sets the stage for mutual eradication - or the end of morality altogether. Choices concerning the future building outcomes of research should not, then, be matters of personal integrity but of relational responsibility - responsibility to the social process out of which morality emerges. As proposed elsewhere (Gergen, 2009) given multiple traditions of the good, moral decision-making might ideally rest on dialogic process - a deliberation among relevant parties. We approach a social pragmatics of morality.

In conclusion, let me suggest that the significance of the natural sciences in society was not derived from their claims to superiority in matters of truth, but in their contribution to the affairs of everyday life. The dramatic investments in science that marked the twentieth century were largely due to the outcomes of such inquiry for curing diseases, harnessing energy, making more effective weapons, creating better building materials, and so on. In effect, the valorization of scientific knowledge derived not from its 
propositions but from its societal outcomes. In my view the social sciences have been all too enamored with the role of truth making, thus thrusting the concern for cultural contribution into a secondary position. We have perhaps naively believed that when our words are inscribed in the journals and books of the disciplines, that such inscriptions will be carried in the minds and hearts of the populace. It is the thrust of the present proposal to reverse the investment - to undertake research as a form of social action, with the words following after. We live in a world in which religious and political conflict threaten the globe, governments are dysfunctional, communities are eroding, longstanding cultural traditions are evaporating, and we struggle with our relationships to our habitat - both natural and technological. It is time for the social sciences to channel their substantial resources of intelligence and ingenuity into creating more flourishing forms of living together.

\section{References}

Alexander, J. 2002. On the social construction of moral universals. European Journal of Social Theory. $5,5-85$.

Altemus, M. 2006. Sex Differences in Depression and Anxiety Disorders: Potential

Biological Determinants. Hormones and Behavior, 50, 534-538.

Appadurai, A. (Ed.) 2001. Globalization. Durham, NC: Duke University Press.

Arendt, H. 1958. The Human Condition. Chicago: Chicago University Press.

Asch, S. E. 1956. Studies of Independence and conformity: A Minority of one against a unanimous majority. Psychological Monographs, 70 (Whole \# 416).

Austin, J. L. 1962. How To Do Things With Words. Oxford: Clarendon.

Badinter, E. 1981. Mother Love, Myth and Reality: Motherhood in Modern History. New York: Macmillan.

Bauman, Z. 2011. Culture in a liquid modern world. Malden, MA: Polity Press.

Berger, P. L., \& Luckmann, T. 1967. The Social Construction of Reality: A Treatise on the Sociology of Knowledge. New York: Doubleday/Anchor.

Bergson, H. 1911. Creative Evolution. (Tr. A. Mitchell). New York: Henry Holt.

Berman, M. 1983. All That is Solid Melts into Air: The Experience of Modernity. New York: Verso.

Boal, A. 1979. Theater of the Oppressed. New York: Urizen Books.

Bojer, M.M., Roehl, H. \& Knuth, M. (2008) Mapping Dialogue: Essential Tools for Social Change. Chagrin Falls, OH: Taos Institute Publications. 
Bourdieu, P. 1977. Outline for a Theory of Practice. Cambridge: Cambridge University Press.

Breeze, R. 2012. Legitimation in Corporate Discourse: Oil Corporations after Deepwater Horizon. Discourse and Society, 23, 19-33.

Brinkmann, S. 2011. Psychology as a Moral Science. New York: Springer.

Charon, R. 2008. Narrative Medicine: Honoring the Stories of Illness. New York: Oxford University Press.

Clifford, J. 1997. Routes: Travel and Translation in the Late Twentieth Century. Cambridge: Harvard University Press.

Coates, J. 2013. The Discursive Production of Everyday Heterosexualities. Discourse and Society, 24, $536-552$.

Cooperrider, D. \& Whitney, D. 2005. Appreciative Inquiry: A Positive Revolution in Change. San Francisco: Barrett-Koehler.

Denzin, N. \& Lincoln, Y. (Eds.) 2011. The Sage Handbook of Qualitative Research. $4^{\text {th }}$ ed. Thousand Oaks, CA: Sage.

Engestrom, Y. 2010. From Teams to Knots. Activity-Theoretical Studies of Collaboration and Learning at Work. Cambridge, UK: Cambridge University Press.

Eitzen, D.S., \& Zinn, M.B. 2011. Globalization: The transformation of social worlds. Independence, KY: Cengage.

Fine, M. \& Torres, M.E. 2006. Intimate Details, Participatory Action Research in Prison. Action Research, 4, 253-269.

Foucault, M. 1979. Discipline and Punish. New York: Vintage.

Friere, P. 1970. Pedagogy of the Oppressed. (Originally published in 1968; 1970). (Trans. Myra Ramos). New York: Continuum.

Gergen, K.J. 1973. Social Psychology as History. Journal of Personality and Social Psychology, 26, 309-320.

Gergen, K.J. 2000. The Saturated Self: Dilemmas of Identity in Everyday Life. (Originally published in 1991) New York: Basic Books.

Gergen, K.J. 2009. Relational Being: Beyond Self and Community. New York: Oxford University Press. 
Gergen, K.J. 2014. Pursuing Excellence in Qualitative Inquiry. Qualitative Psychology, 1, 49-60.

Gergen, M., \& Gergen, K.J. 2012. Playing with Purpose: Adventures in Performative Social Science. Walnut Grove, CA: Left Coast Press.

Gergen, M. M. 2012. Woman as Spectacle. In M.M. Gergen \& K.J. Gergen, (Eds.) Playing with Purpose: Adventures in Performative Social Science. Walnut Grove, CA: Left Coast Press, pp. 148-156.

Giddens, A. 2000. Runaway World: How Globalization is Reshaping our Lives. New York: Routledge.

Gove, W.R. 1975. Labeling of Deviance: Evaluating a Perspective. Hoboken, NJ: Wiley.

Gray, R., \& Sinding, C. 2002. Standing Ovation: Performing Social Science Research About Cancer. Walnut Creek, CA: AltaMira Press.

Gustafson, B., Finne, H., \& Oscarrson, B. (Eds.) 2001. Creating Connectedness: The Role of Social Research in Innovation Policy. Amsterdam: John Benjamins.

Hacking, I. 2000. The Social Construction of What. Cambridge, MA: Harvard University Press.

Hardison, O.B. Jr. 1990. Disappearing Through the Skylight: Culture and Technology in The Twentieth Century. New York: Penguin Books.

Harlow, H.F., Dodsworth, R., \& Harlow, M.K. 1965. Total Social Isolation in Monkeys. Proceedings of the National Academy of Sciences, 54. No. 1, 90-97.

Harlow, H.F., \& Suomi, S.J. 1971. Social Recovery by Isolation-Reared Monkeys. Proceedings of the National Academy of Sciences, 68. No. 7, 1534-1538.

Hassan, Z. (2014) The Social Labs Revolution: A New Approach to Solving our Most Complex Problems. San Francisco: Berrett-Koehler.

Hegel, G.F. 1989. The Science of Logic. (originally published in 1832). Amherst, NY: Humanity Books.

Herzig, M, \& Chasin, L. 2005. Fostering Dialogue across Divides: A Nuts and Bolts Guide from the Public Conversations Project.

http://www.publicconversations.org/docs/resources/Jams_website.pdf

Ingold, T. 2011. Being Alive: Essays on Movement, Knowledge and Description.

London: Routledge.

Ingrids, H. (2014) Blame-account Sequences in Child Custody Disputes. Discourse and Society, 25, $47-$ 64. 
Kahane, A. (2012) Transformative Scenario Planning: Working Together to Change the Future. San Francisco: Berrett-Koehler.

Kahneman, D., Slovic, P. \& Twersky, A. 1982. Judgment under uncertainty: Heuristics and biases. New York: Cambridge University Press.

Karlsson, L.E. 1969. Democracy in the Workplace. Kalmar: Prisma.

Kavanagh, D. 2004. Ocularcentrism and its others: A Framework for Metatheoretical Analysis. Organization Studies. 25, 445-464.

Kirschner, S.R., \& Martin, J. (Eds.) 2010. The Sociocultural Turn in Psychology. New York: Columbia University Press.

Koenig, A.M. \& Eagly, A.H. 2014. Evidence for the Social Role Theory of Stereotype Content: Observations of groups' roles shape stereotypes. Journal of Personality and Social Psychology. 107, 371392.

Kowalski, R.J., Harmon, J. Yorks, L. \& Kowalski, D. 2003. Reducing workplace stress and aggression: An action research project at the US. Department of Veteran Affairs. Human Resource Planning, 26, 39-53.

Kuhn, T. 1962. The Structure of Scientific Revolutions. Chicago: Chicago University Press.

Levin, D.M. 1993. Modernity and the Hegemony of Vision. Berkeley: University of California Press.

Luhmann, N. 1996. Social Systems. (Trans. J. Bednarz \& D. Baeker.) Palo Alto: Stanford University Press.

Luhmann, N. 2012. Theory of Society. V.1. Cultural Memory in the Present. (Trans. R. Barrett.) Palo Alto: Stanford University Press.

Lykes, M. B. 2001. Creative arts and photography in participatory action research in Guatamala. In P. Reason and H. Bradbury (Eds.) Handbook of Participatory Action Research. Thousand Oaks, CA: Sage, pp. 363-371.

MacIntyre, A. (1981) After Virtue: A Study in Moral Theory. South Bend, IN: University of Notre Dame Press.

Maglajlic, R.A., \& Tiffany, J. 2006. Participatory Action Research with Youth in Bosnia and Herzegovina. Journal of Community Practice. 14, 163-181.

Mani, T.M., Bedwell, J.S. \& Miller, L.S. (2005) Age-related Decrements on a Brief Continuous Performance Test. Archives of Clinical Neuropsychology, 5, 575-586. 
Marshak, R. J., \& Grant, D. 2008. Organizational Discourse and New Organization Practices, British Journal of Management, 19,s1,S7-S19.

Martin-Baro, I. 1994. Writings for a Liberation Psychology. (Edited by A. Aron and S. Corne) Cambridge: Harvard University Press.

McDonald, M., Pietsch, T., \& Wilson, J. (2010) Ontological Insecurity: A Guiding Frame for Borderline Personality disorder. Journal of Phenomenological Psychology. 41, 85-105.

Milgram, S. 1963. Behavioral Study of Obedience. Journal of Abnormal and Social Psychology. 67, 371-378.

Piaget, J. \& Inhelder, B. 1969. The Psychology of the Child. New York: Basic Books.

Putnam, H. 2002. The Collapse of the Fact/Value Dichotomy. Cambridge: Harvard University Press.

Quineau. R. 1981. Exercises in Style. New York: New Directions.

Reason, P., \& Bradbury, H. 2008. Sage Handbook of Action Research. London: Sage.

Rogers, D. T. 2011. Age of fracture, Cambridge, MA: Belknap Press.

Rorty, R. 1979. Philosophy and the Mirror of Nature. Princeton: Princeton University Press.

Russell, G., \& Bohan, J. 1999. Hearing Voices: The Use of Research and the Politics of Change. Psychology of Women Quarterly, 23, 403-418.

Richardson, F.C., Fowers, B. J. \& Guignon, C.B. 1999. Reinvisioning Psychology: Moral Dimensions of Theory and Practice. San Francisco: Jossey Bass.

Saldaña, J. 2011. Ethnotheater: Research from Page to Stage. Walnut Grove, CA: Left Coast Press.

Salomon, G. 1997. Distributed Cognitions: Psychological and Educational Considerations. New York, Cambridge, UK: Cambridge University Press.

Saussure, F. 1916. Cours de Linguistique Générale (Trans. C. Bally and A. Sechehaye, with the collaboration of A. Riedlinger) Lausanne and Paris: Payot.

Sayad, A. 2004. The Suffering of the Immigrant. London: Polity.

Scott, B.G. \& Weems, C.F. (2013) Natural Disasters and Existential Concerns: A Test of Tillich's Theory of Existential Anxiety. Journal of Humanistic Psychology. 53, 114-128.

Seikkula, J., \& Arnkil, T.E. 2006. Dialogic Meetings in Social Networks. London: Karnac. 
Simpson, P., \& Mayr, A. (Eds.) 2010. Language and Power: A Resource Book for Students. London: Routledge.

Szuchman, L.T., \& Muscarella, F. 2000. Psychological Perspectives on Human Sexuality. Hoboken, NJ: Wiley.

Tekin, B. 2010. Representations and Othering in Discourse: The Construction of Turkey in the EU Context. Amsterdam: John Benjamins.

Wamba, N.G. (2011) Developing an Alternative Epistemology of Practice: Teacher's Action Research as Critical Pedagogy. Action Research, 9, 162-178.

Waterman, H., Tillen, D., Dickson, R., \& de Konig, K. 2001. Action Research: A systematic review and assessment for guidance. Health Technology Assessment, 5 (23).

Watkins, M., \& Shulman, H. 2010. Toward Psychologies of Liberation. London: Palgrave Macmillan.

Wertz, F. J. 2011. The Qualitative Revolution in Psychology. The Humanistic Psychologist. 39, 77-104.

Whitaker, R. 2010. Anatomy of an Epidemic. New York: Crowne Press.

Whitehead, A.N. 1979. Process and Reality: An Essay on Cosmology (originally published in 1929) New York: Free Press.

Willig, C. 1999. Applied Discourse Analysis: Social and Psychological Interventions. Buckingham: Open University Press.

Winch, P. 1958. The Idea of a Social Science and its Relationship to Philosophy. New York: Humanities Press. 